\title{
Successful Lung Transplant After Prolonged Extracorporeal Membrane Oxygenation (ECMO) in a Child With Pulmonary Hypertension: A Case Report
}

\author{
Cecile Tissot, ${ }^{1}$ Walid Habre, ${ }^{1}$ Paola Soccal, ${ }^{2}$ Maja Isabel Hug, ${ }^{3}$ Dominique Bettex, ${ }^{3}$ Michel Pellegrini, ${ }^{1}$ \\ Yacine Aggoun, ${ }^{1}$ Anne Mornand, ${ }^{1}$ Afksendyios Kalangos, ${ }^{1}$ Peter Rimensberger, ${ }^{1}$ and Maurice Beghetti ${ }^{1,}{ }^{*}$ \\ ${ }^{1}$ Department of the Child and Adolescent, Children's University Hospital of Geneva, Geneva, Switzerland \\ ${ }^{2}$ Division of Pneumology, University Hospital of Geneva, Geneva, Switzerland \\ ${ }^{3}$ Institute of Anesthesiology, University Hospital of Zurich, Zurich, Switzerland \\ "Corresponding author: Maurice Beghetti, Department of the Child and Adolescent, Children's University Hospital of Geneva, Geneva, Switzerland. Tel: +41-223724580, Fax: \\ +41-223824546, E-mail: maurice.beghetti@hcuge.ch
}

Received 2015 August 18; Revised 2015 October 23; Accepted 2015 November 07.

\begin{abstract}
Introduction: The use of extracorporeal membrane oxygenation (ECMO) is considered a risk factor for, or even a potential contraindication to, lung transplantation. However, only a few pediatric cases have been described thus far.

Case Presentation: A 9-year-old boy with idiopathic pulmonary arterial hypertension developed cardiac arrest after the insertion of a central catheter. ECMO was used as a bridge to lung transplantation. However, after prolonged resuscitation, he developed medullary ischemia and medullary syndrome. After 6 weeks of ECMO and triple combination therapy for pulmonary hypertension, including continuous intravenous prostacyclin, he was weaned off support, and after 2 weeks, bilateral lung transplantation was performed. At 4 years post-transplant, he has minimal problems. The medullary syndrome has also alleviated. He is now back to school and can walk with aids.

Conclusions: Increasing evidence supports the use of ECMO as a bridge to LT, reporting good outcomes. In the modern era of PAH therapy, it is feasible to use prolonged ECMO support as a bridge to lung transplant, with the aim of weaning off this support; however, its use requires more experience and knowledge of long-term outcomes.
\end{abstract}

Keywords: Pediatrics, Hypertension, Pulmonary, Lung Transplantation, Extracorporeal Membrane Oxygenation (ECMO)

\section{Introduction}

The use of extracorporeal membrane oxygenation (ECMO) has, for a long time, been considered a risk factor for, or even a potential contraindication to, lung transplantation (LT). Although, recent progress has challenged this paradigm, controversy exists. The information of risks associated with ECMO is based on reports of individual case reports or small case series (1), but two large series published recently have reported ECMO as a feasible bridge to LT and with acceptable outcomes $(2,3)$. However, only a few pediatric cases have been reported thus far. Kirshbom et al. reported that long-term outcome is comparable to patients not being on assist devices after support with ECMO (4). Another report states that those children who can be weaned off ECMO support before LT may have an even better chance of survival (5).

\section{Case Presentation}

We present the case of a 9-year-old boy who received prolonged ECMO support after suffering cardiac arrest and eventually underwent double LT successfully. The patient was diagnosed with idiopathic pulmonary arterial hypertension (PAH) at 4 years of age and was considered a nonresponder to vasoreactivity testing. He had initially received sildenafil as part of a randomized controlled trial, with some beneficial effects. However, the family relocated. He was brought to our clinic at 7 years of age. Because of progression of symptoms (fatigue, dyspnea) and an unsatisfactory hemodynamic profile, bosentan was added to his therapy. After an initial improvement in response to the combination therapy, the child showed continuous deterioration. Echocardiography showed severe right ventricular (RV) dysfunction with massively dilated RV compressing the left ventricle. Prostacyclin treatment was suggested to the family, who preferred intravenous to subcutaneous prostacyclin administration.

A Broviac® catheter was inserted to facilitate continuous prostacyclin infusion. Although we recommended insertion under local anesthesia, the family opted for general anesthesia (GA), even after receiving an explanation of the risks associated with GA. GA was administered using a

Copyright @ 2016, Rajaie Cardiovascular Medical and Research Center, Iran University of Medical Sciences. This is an open-access article distributed under the terms of the Creative Commons Attribution-NonCommercial 4.0 International License (http://creativecommons.org/licenses/by-nc/4.0/) which permits copy and redistribute the material just in noncommercial usages, provided the original work is properly cited. 
mix of ketamine, etomidate, and midazolam for induction, along with sevoflurane and fentanyl for maintenance. Cardiac catheterization performed simultaneously showed a pulmonary arterial pressure of $170 / 126 \mathrm{mmHg}$ (mean 140 $\mathrm{mmHg}$ ), a systemic arterial pressure of $98 / 62 \mathrm{mmHg}$ (mean $74 \mathrm{mmHg}$ ), right atrial pressure of $26 \mathrm{mmHg}$, and cardiac index of $1.8 \mathrm{~L} / \mathrm{min} / \times \mathrm{m}^{2}$.

A permanent catheter was inserted; the procedure was uneventful with stable hemodynamics. However, following extubation in the operating room, the child developed laryngospasm followed by a severe pulmonary hypertensive crisis that led to cardiac arrest, unresponsive to maximal cardiopulmonary resuscitation (CPR), including the use of inhaled nitric oxide.

Arterial blood gas analysis showed severe acidosis with $\mathrm{pH} 6.9, \mathrm{PCO}_{2} 5 \mathrm{kPa}, \mathrm{HCO}_{3} 6.9 \mathrm{mmol}, \mathrm{BE}-24.6 \mathrm{mmol} / \mathrm{L}$, and lactate $15 \mathrm{mmol} / \mathrm{L}$. Decision was taken to start ECMO. After femoral veno-arterial cannulation with retrograde perfusion of the femoral artery, ECMO was started 60 minutes after CPR had been initiated. Abdominal compression and head cooling were used during CPR to ensure brain oxygenation. Immediately after the initiation of ECMO, spontaneous cardiac activity was restored.

ECMO was first initiated as a bridge to LT. An atrioseptostomy was performed and intravenous prostacyclin was started to allow for potential weaning from the support when possible.

The patient developed several complications related to prolonged CPR: transient acute renal failure; left anterior leg compartment syndrome requiring emergency fasciotomy; and an unresolving anterior medullary syndrome at the level of L4 - L5 immediately after medullary ischemia, without evidence of brain damage on cerebral computed tomography. Spinal magnetic resonance imaging was not possible as the patient was on ECMO. After 2 days of CPR, the child was kept on mild sedation; he showed normal brain function but developed complete paraplegia. Evoked potentials of the lower limbs were absent, consistent with anterior medullary ischemia at the thoracic or lumbar level. Five days after the event, he showed absence of abdominal cutaneous and lower limb reflexes along with flask paraplegia. Proprioception was preserved. This sensori-motor dissociation was in favor of an anterior spinal cord ischemia.

After a long discussion with the transplant team and the ethics committee, and because of the strong desire of the family to pursue LT despite the peripheral neurological damage, he was transferred to the national LT center on ECMO. After 5 weeks of the triple combination therapy including sildenafil, bosentan, and prostacyclin, he could be weaned off ECMO. He developed recurrent lung atelectasis, secondary to bronchial compression by the di- lated pulmonary arteries that prevented extubation. A tracheostomy was therefore performed only 6 weeks after several unsuccessful attempts of extubation. He underwent successful LT 12 weeks after the event. Prophylactic ECMO support was used for 48 hours and thereafter was weaned off without starting any cardiotonic support. Ventilation was completely weaned off 25 days after LT. He was discharged 61 days post-LT to a secondary care hospital, which was close to his home, where a re-education program was initiated. Echocardiography showed progressive and rapid recovery of RV function.

At 4 years post-transplant, he has minimal problems. His medullary syndrome has partially alleviated, but the bladder dysfunction exists. He is back to school and can walk with aids!

\section{Discussion}

This case is of interest for several reasons:

Prolonged ECMO support is feasible as a bridge to LT in children with end-stage cardiopulmonary disease, and even for idiopathic PAH. Recent evidence supports the use of this strategy, reporting good long-term outcome (1-3, 57). This case also illustrates that ECMO support may be weaned off with aggressive PAH therapy, including triple combination therapy and atrioseptostomy. Septostomy was performed as an emergency procedure and the communication was not sized. Sizing is indeed difficult, and relevant data in pediatrics are not available. Another possible approach would be to perform a Potts shunt for decompressing the RV, but because of scarce data available at the time of managing this case (no reports of patients on ECMO) (8), the procedure was considered high risk with the patient on ECMO. A current publication, nevertheless, suggests (9) that this approach merits consideration and further studies are required.

Recently, Sitbon et al. have shown dramatic improvement with the triple combination therapy in severe PAH (10). A similar approach may be used for aggressively decreasing the RV afterload in patients after cardiac arrest, aiming to wean off ECMO if the patient is not receiving complete treatment for PAH. In the past few years, we have successfully used this approach in postoperative PAH after repair of congenital heart disease. The possibility of ECMO weaning may increase the potential success of LT, as reported by several groups $(2,5)$. ECMO can be used in conscious adults and children. In pediatric patients, ECMO requires the collaboration and an extremely good interaction with the patient, as was the case with our patient. This may not be always possible and would depend on the age and ability of the patient to collaborate. This strategy is of interest if prolonged circulatory support is necessary 
$(6,11)$. Finally, in our patient, double LT was performed despite a post-CPR medullary syndrome, The decision to transplant a patient with potential paraplegia remains a difficult decision and should be taken on case-by-case basis (12). Such a decision is indeed difficult and is taken on a case-by-case basis.

Our patient was treated several years ago with sequential oral combination therapy, which was initiated because of continuous deterioration. A more aggressive approach is supported by current adult and pediatric data, but was not considered routine a few years ago. It must be remembered that at the time of treating our patient, no pediatric treatment had been approved for $\mathrm{PAH}$, and therefore we used the sequential combination reported for adults (13).

Another learning from this case is that intravenous prostacyclin should probably be initiated before the insertion of the central catheter. Even though no controlled data are currently published to support this approach, we strongly suggest that patients with severe PAH (functional class 4) should first be stabilized using the triple combination therapy before GA or cardiac catheterization. Close surveillance after the procedure is another critical element in either intensive care or step-down units. GA has been reported to be a potential risk factor in pediatric $\mathrm{PAH}$ (14).

Our group has previously described the possible use of hypnosis to insert the central line in this setting, but this was not an option available for our pediatric case (15).

ECMO support must be available in pediatric centers that manage patients requiring invasive procedures such as central catheter insertion or cardiac catheterization, i.e. procedures often performed under GA. ECMO may offer support to the patients as a bridge to LT when needed.

Another important learning is the high probability of recovery of severely impaired RV function in the setting of PAH once RV afterload is normalized. This has been already described in LT, and it allows for double LT and not heart-lung transplantation, but after pulmonary endarterectomy (16).

Increasing reports support the use of ECMO as a bridge to LT, with good post-transplant outcomes. In the modern era of PAH therapy, it is feasible to use prolonged ECMO as a bridge to LT in pediatric patients who suffer cardiac arrest, with the aim of weaning this support. However, it requires substantial experience and long-term results to support the treatment successfully offered to this single patient.

\section{Footnote}

Authors' Contribution: All authors have been involved in the treatment of this patient, have read the manuscript, made comments and suggestions, and have approved the final version. Cecile Tissot and Maurice Beghetti were in charge of the patient and wrote the report. Paola Soccal is the lung transplant person in Geneva. Maja Isabel Hug and Dominique Bettex were in charge of the patient at the transplant center and in charge of the immediate pre and post transplant care. Yacine Aggoun did perform the cardiac catheterization. Afksendyios Kalangos inserted the ECMO. Anne Mornand is the pediatric pneumologist and Peter Rimensberger is the pediatric intensivist. Walid Habre and Michel Pellegrini were the anesthetists in charge of the patient.

\section{References}

1. Javidfar J, Bacchetta M. Bridge to lung transplantation with extracorporeal membrane oxygenation support. Curr Opin Organ Transplant. 2012;17(5):496-502. doi: 10.1097/MOT.0b013e328357fa4f. [PubMed: $22941324]$.

2. Javidfar J, Brodie D, Iribarne A, Jurado J, Lavelle M, Brenner K, et al. Extracorporeal membrane oxygenation as a bridge to lung transplantation and recovery. J Thorac Cardiovasc Surg. 2012;144(3):716-21. doi: 10.1016/j.jtcvs.2012.05.040. [PubMed: 22795457].

3. Toyoda Y, Bhama JK, Shigemura N, Zaldonis D, Pilewski J, Crespo M, et al. Efficacy of extracorporeal membrane oxygenation as a bridge to lung transplantation.J Thorac Cardiovasc Surg. 2013;145(4):1065-70. doi: 10.1016/j.jtcvs.2012.12.067. [PubMed: 23332185].

4. Kirshbom PM, Bridges ND, Myung RJ, Gaynor JW, Clark BJ, Spray TL. Use of extracorporeal membrane oxygenation in pediatric thoracic organ transplantation. J Thorac Cardiovasc Surg. 2002;123(1):130-6. [PubMed: 11782766].

5. Puri V, Epstein D, Raithel SC, Gandhi SK, Sweet SC, Faro A, et al. Extracorporeal membrane oxygenation in pediatric lung transplantation. J Thorac Cardiovasc Surg. 2010;140(2):427-32. doi: 10.1016/j.jtcvs.2010.04.012. [PubMed: 20538306].

6. Fuehner T, Kuehn C, Hadem J, Wiesner O, Gottlieb J, Tudorache I, et al. Extracorporeal membrane oxygenation in awake patients as bridge to lung transplantation. Am J Respir Crit Care Med. 2012;185(7):763-8. doi: 10.1164/rccm.201109-1599OC. [PubMed: 22268135].

7. Lang G, Taghavi S, Aigner C, Renyi-Vamos F, Jaksch P, Augustin V, et al. Primary lung transplantation after bridge with extracorporeal membrane oxygenation: a plea for a shift in our paradigms for indications. Transplantation. 2012;93(7):729-36. doi: 10.1097/TP.ob013e318246f8e1. [PubMed: 22415051].

8. Blanc J, Vouhe P, Bonnet D. Potts shunt in patients with pulmonary hypertension. N Engl J Med. 2004;350(6):623. doi: 10.1056/NEJM200402053500623. [PubMed:14762197].

9. Baruteau A, Belli E, Boudjemline Y, Laux D, Levy M, Simonneau G, et al. Palliative Potts shunt for the treatment of children with drugrefractory pulmonary arterial hypertension: updated data from the first 24 patients. Eur J Cardiothorac Surg. 2015;47(3):e105-10.:e105-10. [PubMed: 25475943].

10. Sitbon O, Jaïs X, Savale L, Cottin V, Bergot E, Macari EA, et al. Upfront triple combination therapy in pulmonary arterial hypertension: a pilot study. Eur Respir J. 2014;43(6):1691-7. [PubMed: 24627535].

11. Wiesner O, Hadem J, Sommer W, Kühn C, Welte T, Hoeper MM. Extracorporeal membrane oxygenation in a nonintubated patient with acute respiratory distress syndrome. Eur Respir J. 2012;40(5):1296-8. [PubMed: 22878882].

12. Masson C, Pruvo JP, Meder JF, Cordonnier C, Touze E, De La Sayette V, et al. Spinal cord infarction: clinical and magnetic resonance imaging findings and short term outcome. J Neurol Neurosurg Psychiatry. 2004;75(10):1431-5. doi: 10.1136/jnnp.2003.031724. [PubMed: 15377691]. 
13. Galie N, Humbert M, Vachiery J, Lang I, Torbicki A, Simonneau G, et al. 2015 ESC/ERS guidelines for the diagnosis and treatment of pulmonary hypertension: the joint task force for the diagnosis and treatment of pulmonary hypertension of the european society of cardiology (ESC) and the european respiratory society (ERS) endorsed by: association for european paediatric and congenital cardiology (AEPC), international society for heart and lung transplantation (ISHLT). Eur Heart J. 2015. doi:10.1093/eurheartj/ehv317.

14. Shukla AC, Almodovar MC. Anesthesia considerations for children with pulmonary hypertension. Pediatr Crit Care Med. 2010;11(2 Suppl):S70-3. doi: 10.1097/PCC.0b013e3181c76c6e. [PubMed: 20216167].
15. von Ungern-Sternberg BS, Habre W. Hypnosis as an alternative to avoid general anesthesia in a child with severe pulmonary arterial hypertension. Paediatr Anaesth. 2009;19(2):182-3. doi: 10.1111/j.14609592.2008.02800.x. [PubMed: 19207914].

16. Reesink HJ, Marcus JT, Tulevski I, Jamieson S, Kloek JJ, Vonk Noordegraaf A, et al. Reverse right ventricular remodeling after pulmonary endarterectomy in patients with chronic thromboembolic pulmonary hypertension: utility of magnetic resonance imaging to demonstrate restoration of the right ventricle. J Thorac Cardiovasc Surg. 2007;133(1):58-64. doi: 10.1016/j.jtcvs.2006.09.032. [PubMed: 17198781]. 